\title{
Producción de biogas a partir de Biomasa
}

\author{
Edwin Antonio Reyes Aguilera ${ }^{1}$
}

\section{RESUMEN}

La finalidad de este trabajo investigativo es evaluar la producción de biogás a partir de la biomasa (pasto estrella Cynodon plectostachyus K.Schum), de acuerdo a sus parámetros característicos de funcionamiento por medio de la digestión anaerobia no controlada y el método de balance de masa por secado en hornos de laboratorio. Es una investigación cuantitativa según su enfoque, con un nivel de profundidad según su tipología: exploratoria y descriptiva. La muestra del estudio es probabilística. Los instrumentos utilizados fueron: una guía estructurada para la recolección de datos, se utilizaron hornos eléctricos, balanzas analíticas, termómetros, phachimetros. Los resultados obtenidos muestran que la biomasa evaluada es un excelente sustrato para la producción de biogás siempre y cuando los parámetros que caracterizan la digestión anaerobia sean los adecuados para dicho proceso, el cual se logra construyendo un biodigestor con las características físicas y técnicas apropiadas. Se concluye que los parámetros de funcionamiento evaluados dan la pauta de que se pueden mejorar las condiciones del proceso anaerobio utilizando biomasa por lo que es un tema que se puede seguir investigando e inclusive hacer proyectos piloto en zonas rurales dado que nuestras condiciones climáticas tropicales, favorecen grandemente para la implementación de esta tecnología, debido a que a mayor temperatura, se produce una mayor degradación de la materia orgánica y disminuye el tamaño de las estructuras que requiere el sistema.

Palabras claves: Biodigestor, sustrato orgánico, digestión anaerobia

Recibido: 10 de marzo de 2016

Aceptado: 4 de abril de 2016

1 UNAN-Managua/FAREM-Estelí. Correo Electrónico: edwinra11@yahoo.es 


\title{
Biogas production from Biomass
}

\begin{abstract}
The purpose of this research is to evaluate the production of biogas from biomass (star grass Cynodon plectostachyus K.Schum), according to its characteristic operating parameters via uncontrolled anaerobic digestion and mass balance method by drying in laboratory heaters. This is a quantitative, exploratory and descriptive research. The sampling is probabilistic. The instruments used were: a structured guide for data collection, electric ovens, analytical set of scales, thermometers and phachimetros. The results show that the evaluated biomass is an excellent substrate for biogas production as long as the parameters characterizing anaerobic digestion are the proper ones for this process, which is achieved by making a digester with the physical characteristics and appropriate techniques. It is concluded that the parameters evaluated show that can improve the conditions of the anaerobic process using biomass so it is an issue that can further be explore and even to design pilot projects in rural areas since our tropical climate conditions favor greatly to the implementation of this technology, because the higher the temperature, further degradation of organic material occurs and decreases the size of the structures required by the system .
\end{abstract}

Keywords: Biodigestor, organic substrate, anaerobic digestion. 


\section{INTRODUCCIÓN}

Desde que el hombre aprendió a emplear el fuego, la cocción de alimentos ha llegado a ser una de las actividades fundamentales para su subsistencia. Para esto se han utilizado diferentes combustibles, entre ellos la biomasa vegetal.

Desde hace muchos siglos, la producción de biogás se viene realizando en países como China y la India (Werner, 1983). La producción de biogás, a través de la fermentación anaeróbica, es uno de los procesos biológicos más frecuentes usados por la naturaleza para descomponer los materiales orgánicos. En él se encuentran gases como metano, dióxido de carbono, hidrógeno y trazas de otros gases (pero no amoníaco). La fermentación anaeróbica transcurre con menor desprendimiento calorífico, circunstancia que determina un mayor contenido energético y un incremento en la retención de nitrógeno original de los residuos digeridos (Singh, 1974). El proceso es sumamente complejo en el que interviene un elevado número de especies bacterianas, productoras o no de metano, que contribuyen de algún modo a la formación de este gas.

Con la constante subida de los precios de los combustibles fósiles, unido a la crisis medioambiental que se genera, se vuelve a valorar la utilidad de los desechos orgánicos y su aprovechamiento para obtener combustibles de ellos. De esta manera empieza a entenderse así lo poco sensato que resulta importar o extraer combustibles fósiles de zonas remotas para obtener una energía la cual puede conseguirse en buena medida de los materiales que desechamos habitualmente.

La producción de biogás a partir de biomasa forestal tiene como propósito coadyuvar a la reducción de gases que provocan el efecto invernadero del planeta, pero también es una alternativa que permite obtener energía para cubrir las necesidades de combustible en los hogares sobre todo de la zona rural de nuestro país, en granjas pecuarias y resolver problemas como la disposición final de desechos, malos olores, fauna nociva, transmisión de enfermedades y contaminación de mantos freáticos. Además de que se puede obtener biofertilizantes a partir de los lodos residuales.

Esta investigación se realizó de manera práctica y aplicada, y consistió en experimentos a escala de laboratorio que se llevaron a cabo una evaluación de los afluentes de biodigestores a base de biomasa (pasto estrella Cynodon plectostachyus K.Schum), la producción generada y los parámetros de la materia orgánica que se utilizaron.

\section{MATERIALES Y METODOS}

El estudio se llevó a cabo en el laboratorio de energías renovables de la Facultad Regional Multidisciplinaria (Farem - Estelí), donde se diseñaron y se construyeron tres biodigestores tipo Bach, para evaluar el sustrato orgánico y la producción de biogás aprovechando la biomasa, (pasto estrella).

Es una investigación cuantitativa según su enfoque, con un nivel de profundidad según su tipología: Exploratoria y descriptiva. Los diferentes tipos de pastos que crecen el área urbana y rural, en esta investigación se caracterizó el pasto Estrella (Cynodon plectostachyus K.Schum).

Se aplicó el muestreo probabilístico debido a que todos los diferentes tipos de pastos tienen la misma probabilidad de ser elegidos para formar parte la muestra. El tamaño de la muestra es:

- 150 grs de pasto Estrella (Cynodon plectostachyus K.Schum) para su caracterización en el horno.

- 14 Libras de pasto Estrella(Cynodon plectostachyus K.Schum) para la producción de biogás. 


\section{Fases de la investigación}

Para alcanzar los objetivos planteados, se ha utilizado un proceso metodológico dividido en tres etapas: Diseño y construcción de los biodigestores, someter la fracción orgánica en un proceso anaerobio y la evaluación de los parámetros de funcionamiento.

\section{Etapa de campo}

OE 1. Caracterizar las propiedades de la materia orgánica, por medio de un balance de masa, tanto a través de métodos usando hornos de secado y de combustión.

Determinación de solidos volátiles: Se realizó el pesaje de 150 gramos de sustrato de pasto estrella (Cynodon plectostachyus K.Schum) y se introdujeron en 3 capsulas de porcelana en un horno eléctrico a una temperatura de $105 \mathrm{oC}$, durante 8 horas para eliminar la humedad contenida en las mismas.

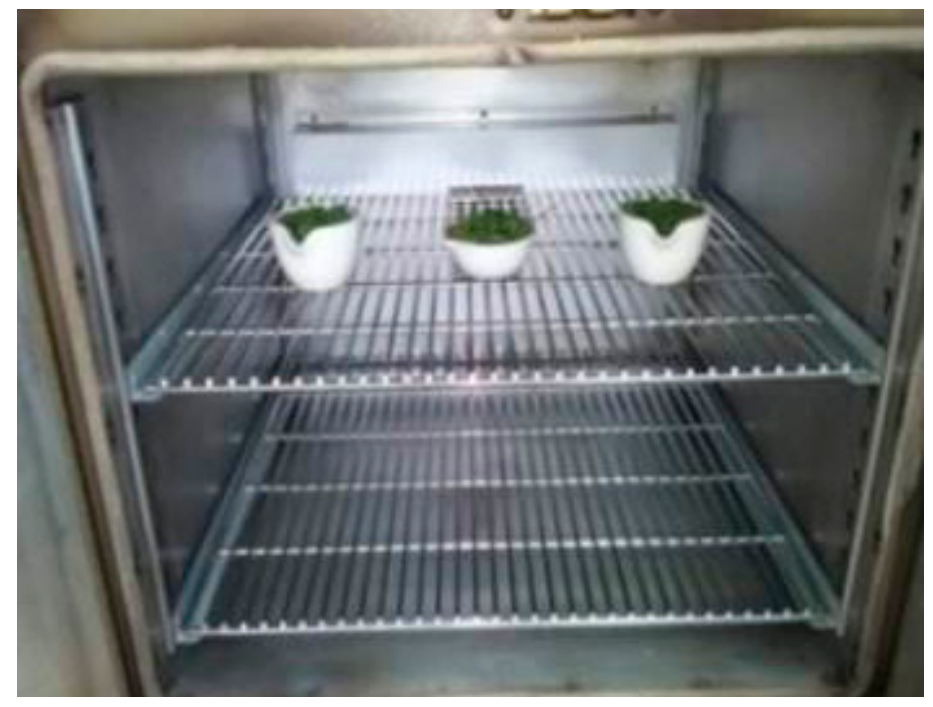

Fig. 1 Sustrato en horno a 105 oC

Luego se dejaron enfriar a temperatura ambiente y posteriormente se transfirieron a la balanza analítica y se pesaron nuevamente para conocer el porcentaje de humedad y masa seca respectivamente, para luego ser introducidas al horno eléctrico a una temperatura de $550 \mathrm{oC}$ durante 14 horas y seguidamente se retiraron las muestras, se dejaron enfriar a temperatura ambiente se pesaron y esto nos permitió conocer el porcentaje de cenizas y el contenido de solidos volátiles presente en las muestras.

El porcentaje de humedad: se determinó utilizando la siguiente formula:

$$
\mathrm{M}_{\mathrm{b}}=\mathrm{M}_{\mathrm{h}}+\mathrm{M}_{\mathrm{s}} \quad \text { ec. } 1
$$

Dónde: Mb es la masa bruta o total, Mh masa húmeda, Ms masa seca. El secado a $105{ }^{\circ} \mathrm{C}$ durante $8 \mathrm{~h}$ se realiza para asegurar la evaporación del agua contenida en el material. A partir de la ec.1 se determinan los porcentajes contenidos de masa húmeda, que se pierde por evaporación tras el secado, y de masa seca, por medio de:

$\mathrm{M}_{\mathrm{rh}} \%=\mathrm{M}_{\mathrm{h}} / \mathrm{M}_{\mathrm{b}} * 100 \%$ y $\mathrm{M}_{\mathrm{rs}} \%=\mathrm{M}_{\mathrm{s}} / \mathrm{M}_{\mathrm{b}} * 100 \%$ ec. 2

Determinación de las cenizas: Este es un procedimiento que se realiza dentro de un horno hermético a una temperatura igual o mayor a $500^{\circ} \mathrm{C}$. Durante esta etapa, la materia orgánica rompe todos sus enlaces pasando por un proceso de pirolisis hasta su gasificación casi total.

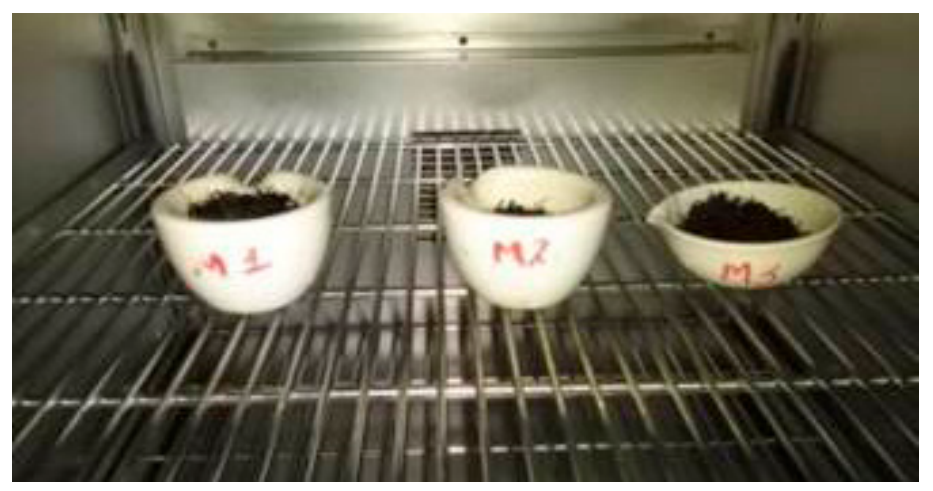

Fig. 2 Sustrato en horno a 550 oC

Cuando esto sucede, la masa seca puede separarse, como efectivamente se conoce, en dos partes: la parte de los sólidos volátiles y la de cenizas. Por cierto, durante la gasificación de la materia las cenizas quedan, y son los sólidos volátiles los que se escapan en forma de 
gas. Entonces, luego de la combustión del material, se procede a medir la masa de las cenizas. La diferencia a la masa seca menos la de cenizas es la masa de los sólidos volátiles:

$$
\mathrm{M}_{\mathrm{sv}}=\mathrm{M}_{\mathrm{s}}-\mathrm{M}_{\mathrm{c}} \quad \text { ec. } 3
$$

Y por analogía con el procedimiento de los porcentajes de contenido en la masa, se obtiene los pesos para los sólidos volátiles y las cenizas en base seca por medio de ec.4:

$\mathrm{M}_{\mathrm{rsv}} \%=\mathrm{M}_{\mathrm{sv}} / \mathrm{M}_{\mathrm{s}} * 100 \%$ y $\mathrm{M}_{\mathrm{rc}} \%=\mathrm{M}_{\mathrm{c}} / \mathrm{M}_{\mathrm{s}} * 100 \%$ ec .4

\section{OE 2. Evaluar los parámetros característicos de funcionamiento del prototipo de Biodigestor tipo Batch.}

Después de haberse llenado los biodigestores con sus respectivas mezclas y relaciones se procedió a la evaluación de sus parámetros tales como:

Grado de acidez: la determinación del $\mathrm{pH}$ se hizo recolectando liquido de la mezcla a través de la válvula conectada en la parte inferior de cada biodigestor, luego se calibraba a cero el medidor de $\mathrm{pH}$, se introducía este en el líquido y digitalmente nos mostraba el valor obtenido.

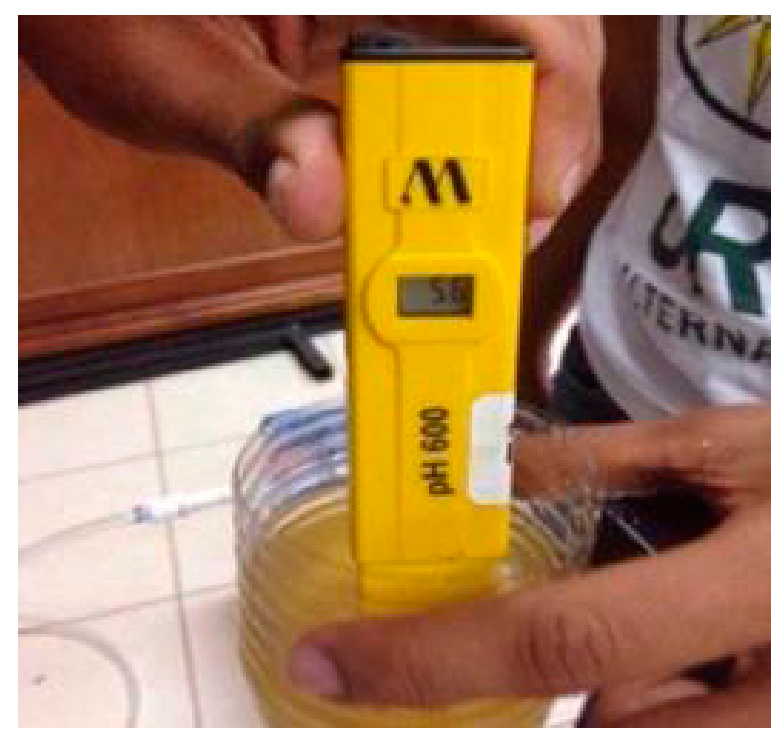

Fig. 3 Medición del pH
Rango de temperatura: La temperatura a la cual estaban sometidos los biodigestores era ambiente y se mantuvo en el régimen mesofilíco, para su verificación y control se insertó en la parte superior de cada biodigestor un termómetro digital.

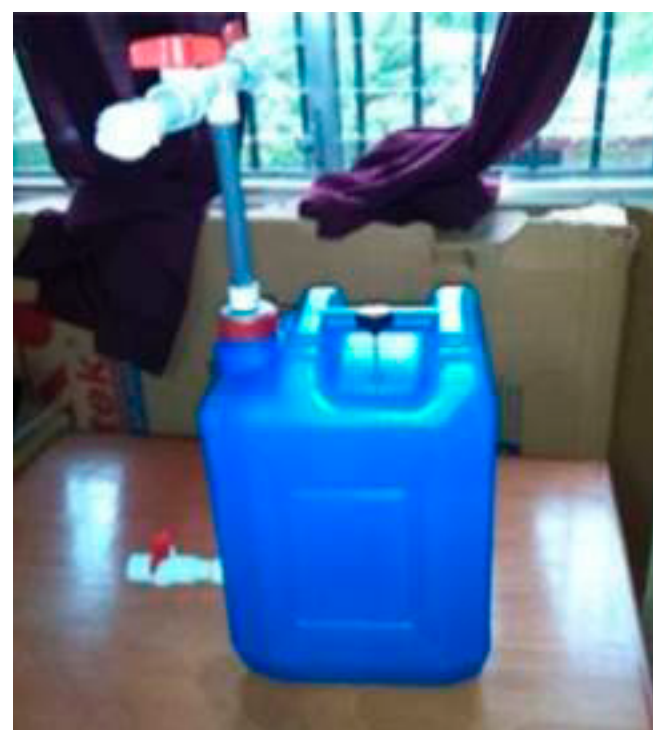

Fig. 4 Mediciones de temperatura

\section{OE 3. Determinar la producción de biogás generada en el biodigestor}

Esta etapa de campo consistió en la recolección de los substratos a utilizar: Biomasa (recolectada en el área de la facultad utilizando machete para su recolecta) y el sustrato de estiércol de vaca, recolectado en una finca cercana a la ciudad de Estelí y con 10 minutos aproximados de deposición por parte del ganado, lo que nos permitió obtener una muestra fresca para el estudio.

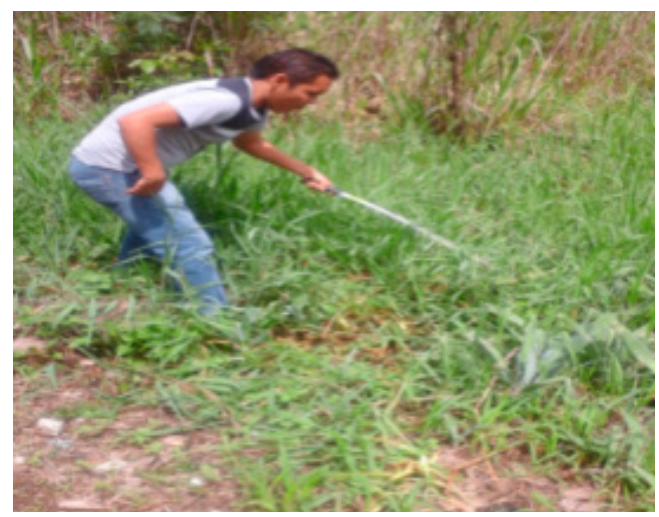

Fig. 5 Recolección de Biomasa forestal 
Se construyeron tres biodigestores tipo batch con una capacidad de 20 litros, primeramente se perforo la parte frontal de estos y se conectó una válvula de seguridad. Los cuales cuentan con una línea de entrada y de salida con sus llaves de abre y cierre además de un sistema de manguera que va unido al neumático cada uno de manera independiente.

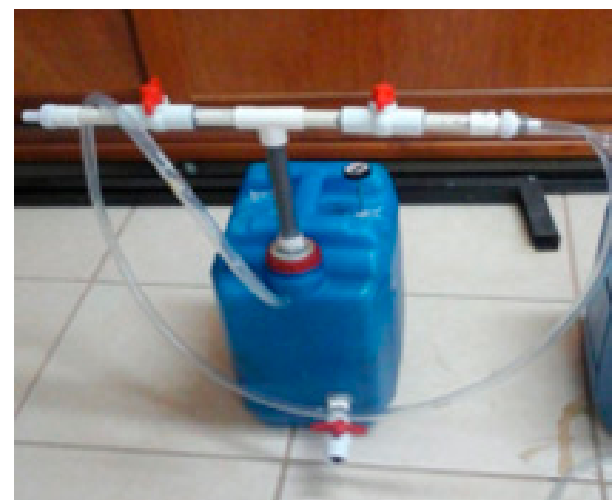

Fig. 6 Llenado de biodigestores

Una vez recolectados los sustratos se sometieron a los reactores tipo batch con sus respectivas mesclas tomando en cuenta que estas permiten la estabilidad en el proceso de digestión anaerobia, al estar equilibrada la cantidad de agua y substrato.

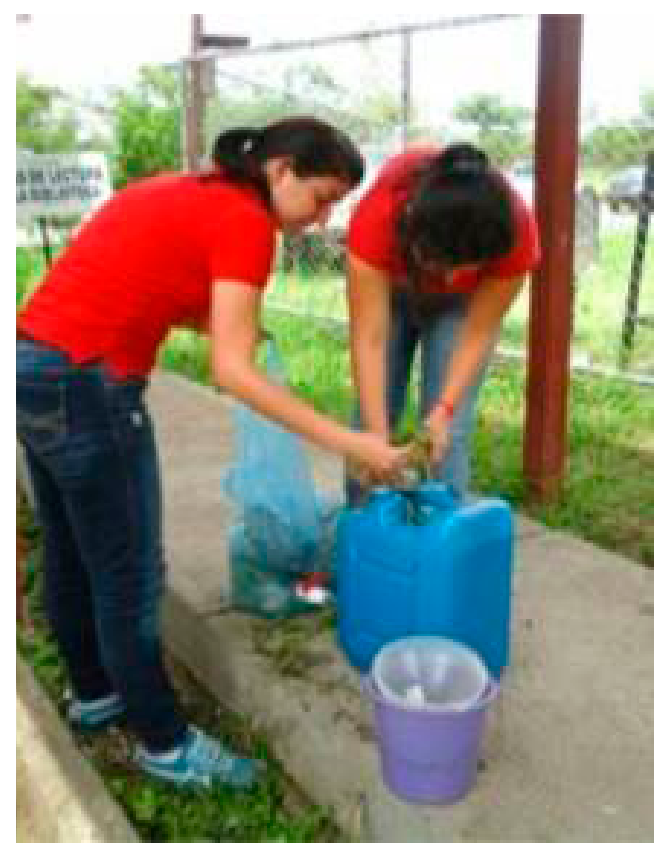

Fig.7 Llenado de biodigestores
Relación 2:1. Se introdujo 8 libra de biomasa, más 100 gramos de gallinaza agregándole 7 litros de agua, teniendo una temperatura inicial de $28{ }^{\circ} \mathrm{C}$.

Relación 3:1. Se introdujo 6 libra de biomasa, agregándole 10 litro de agua, teniendo una temperatura inicial de $28{ }^{\circ} \mathrm{C}$.

Relación 3:1. Se introdujo 5 libras de estiércol de vaca, agregándole 10 litros de agua, teniendo una temperatura $27{ }^{\circ} \mathrm{C}$.

Durante la medición de la producción de los se realizaron mediciones durante varios días, con un tiempo de retención de 7 días desde que se hizo el llenado con los substratos, dos biodigestores con biomasa y uno de ellos empleando estiércol de vaca. Los biodigestores que tienen una capacidad de 20 litros.

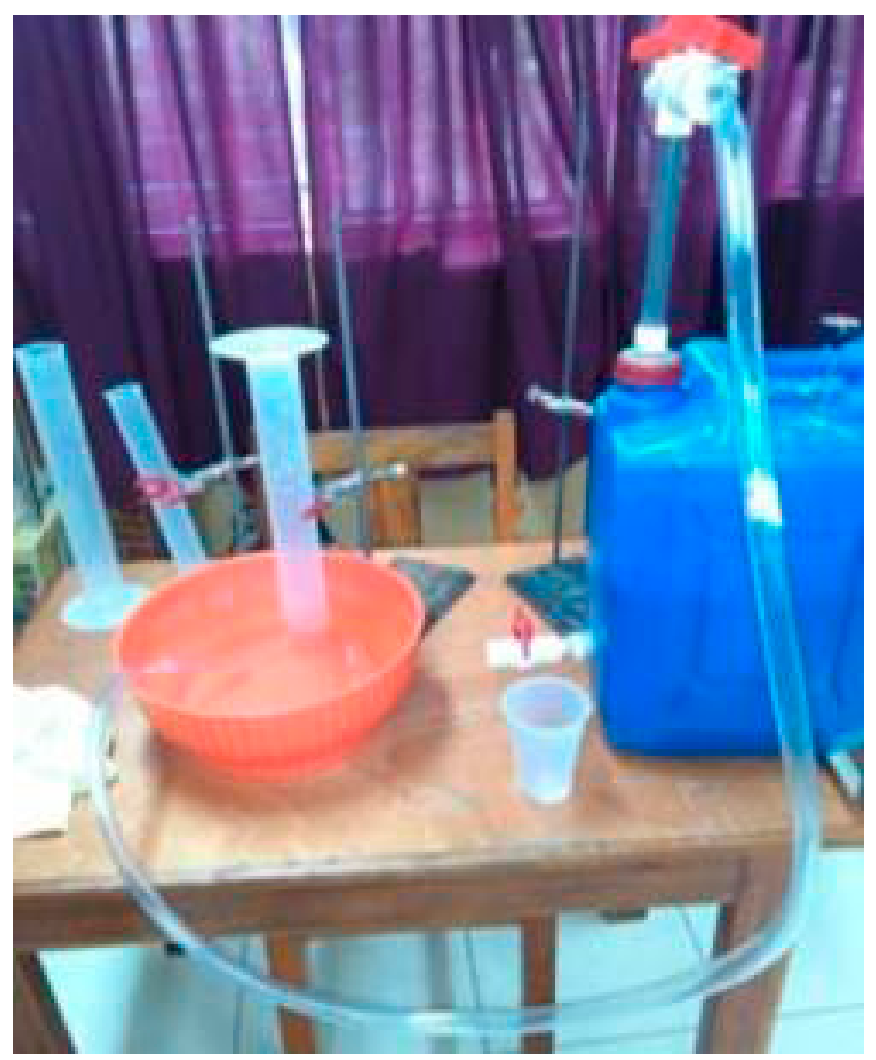

Fig 8 Medicion de producción de biogas

La cantidad de biogás producido se midió utilizando el método de desplazamiento de agua que consiste en introducir la probeta en un recipiente con agua y dentro 
de la probeta se coloca la manguera de salida del gas hasta la parte superior, una vez abiertas la válvulas el gas hace que el nivel de agua de la probeta baje y por lo tanto se mide la cantidad de biogás obtenido en cada una de las muestras; se hizo con este método ya que no había la suficiente presión en el proceso anaerobio para inflar los neumáticos. La sumatoria de todas las mediciones nos dio el total producido.

\section{RESULTADOS Y DISCUCIÓN}

En este apartado se abordará los resultados obtenidos acerca del diseño y construcción de tres reactores tipo batch, construidos en la Facultad Regional Multidisciplinaria (FAREM - ESTELÍ). Así como la evaluación los parámetros de funcionamiento de este tipo de tecnología en el cual se aprovecha la biomasa para la obtención de biogás.

\section{Caracterizar las propiedades de la materia} orgánica, por medio de un balance de masa, tanto a través de métodos usando hornos de secado y de combustión.

Se procedió a realizar las pruebas físicas del sustrato; esto es a través de un balance de masa de los afluentes, tal y como se describe en el diseño metodológico, la tabla 1 muestra los porcentajes de humedad y masa seca de cada sustrato, se introdujeron tres muestras de sustrato con el objetivo de tener resultados confiables, la diferencia obedece a que el Crisoll o capsulas de porcelana utilizado en las muestra 3 es más grueso su espesor, por lo tanto hay una diferencia no tan significativa respecto a las muestras 1 y 2 . Los resultados obtenidos muestran que es mayor la masa húmeda en el sustrato de ganado que en las demás muestras de biomasa, es decir haya más centidad de agua existente en la materia de ganado, además de existir más sólidos totales en las muestras de biomasa (pasto estrella).
Tabla No.1. Muestras de los sustratos (Afluente)

\begin{tabular}{lrrrrr}
\hline $\begin{array}{c}\text { Masa } \\
\text { Húmeda } \\
\text { (gr) }\end{array}$ & $\begin{array}{c}\text { Masa } \\
\text { seca } \\
\text { (gr) }\end{array}$ & $\begin{array}{c}\text { Porcentaje } \\
\text { de } \\
\text { humedad }\end{array}$ & $\begin{array}{c}\text { Porcentaje } \\
\text { de masa } \\
\text { seca (gr) }\end{array}$ & $\begin{array}{c}\text { Porcentaje } \\
\text { de } \\
\text { humedad }\end{array}$ & $\begin{array}{c}\text { Porcentaje } \\
\text { de masa } \\
\text { seca }\end{array}$ \\
\hline Muestra 1 & 50 & 34 & 16 & 68 & 32 \\
Muestra 2 & 50 & 36 & 14 & 72 & 28 \\
Muestra 3 & 50 & 39 & 11 & 78 & 22 \\
$\begin{array}{l}\text { Excreta } \\
\text { de ganado }\end{array}$ & 100 & 86 & 14 & 86 & 14 \\
\hline
\end{tabular}

Mh Se obtiene de ec.1, al despejar Mh y conocida la masa bruta y la masa seca. Masa seca: Se obtiene por medición directa con la balanza. Porcentajes. Se obtienen de las ec.2 Mrh y Mrs, respectivamente.

En la tabla 2 observamos los porcentajes de solidos volátiles y de cenizas obtenidos una vez que las muestran fueron sometidas a $550 \mathrm{oC}$, esto significa que la muestra tres obtuvo mayor porcentaje de cenizas debido a la condición anterior respecto a los crisoles es decir es la que contiene más material que no será transformado durante el proceso y es el peso que queda después del encendido (cenizas), se trata de material biológicamente inerte.

Mientras tanto que los sólidos volátiles son considerados como la materia que realmente es transformada por las bacterias. Es el peso de los sólidos orgánicos quemados cuando el material seco se enciende (se calienta unos $538^{\circ} \mathrm{C}$ ), en este caso la muestra 3 obtuvo mejor rendimiento, lo importante en esta evaluación es que sea cualquiera de las muestras, es posible obtener biogás dados los datos obtenidos de solidos volátiles, esto al final es lo más importante de la investigación, poder asegurar con propiedad que se puede generar biogás a través de la digestión anaerobia a partir de biomasa. 
Tabla 2 datos obtenidos en determinación de cenizas

\begin{tabular}{lrrrrr}
\hline Sustratos & $\begin{array}{c}\text { Masa } \\
\text { Seca } \\
\text { (gr) }\end{array}$ & $\begin{array}{c}\text { Sólidos } \\
\text { volátiles }\end{array}$ & $\begin{array}{c}\text { Cenizas } \\
\text { (gr) }\end{array}$ & $\begin{array}{c}\text { Porcentaje } \\
\text { de sólidos } \\
\text { volátiles }\end{array}$ & $\begin{array}{c}\text { Porcentaje } \\
\text { de cenizas }\end{array}$ \\
\hline Muestra 1 & 16 & 11 & 5 & 68.75 & 31.25 \\
Muestra 2 & 14 & 9 & 5 & 64.28 & 35.72 \\
Muestra 3 & 11 & 6 & 5 & 54.54 & 55.46 \\
$\begin{array}{l}\text { Excreta de } \\
\text { ganado }\end{array}$ & 14 & 11 & 3 & 58.57 & 41.43 \\
\hline
\end{tabular}

Sólidos volátiles: Se obtiene por medio de la ec.3 al conocerse la masa seca y la masa de cenizas.

Cenizas. Se mide directamente con la balanza. Los Porcentajes Se obtienen de las ec.4, Mrsv y Mrc, respectivamente.

Evaluar los parámetros característicos de funcionamiento del prototipo de Biodigestor tipo Batch.

\section{Temperatura}

La temperatura durante el tiempo de funcionamiento y evaluación del proceso anaeróbico se mantuvo bajo un régimen mesófílico (entre $20 \mathrm{oC}$ y $40 \mathrm{oC}$ ) el grafico 1 muestra que la temperatura osciló entre $\operatorname{los} 23^{\circ} \mathrm{C}$ a $30^{\circ} \mathrm{C}$, en los tres sistemas realizando la medición por separado en cada sistema anaerobio (ver anexo 2), lo que nos aseguró valores óptimos de eficiencia de producción y tiempo de resistencia. Según la literatura consultada se considera como ideal, las bacterias son más estables y producen sedimentos de alta calidad como fertilizantes.

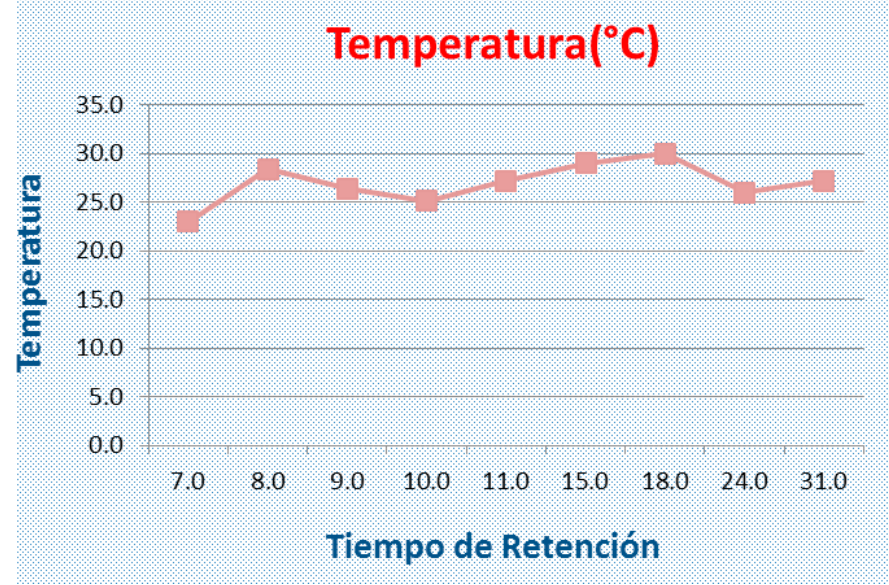

Gráfico $N^{\circ} 1$ Temperatura registrada en los biodigestores

\section{Grado de acidez. Ph}

Una vez estabilizado el proceso fermentativo el $\mathrm{pH}$ se mantuvo en valores que oscilaron entre $6 \mathrm{y}$ algunas veces alcanzo los 8, (los gráficos2, 3, y 4 muestran los resultados del $\mathrm{pH}$ medido en cada biodigestor, ver tabla de valores anexo 2) lo cual permitió se diera la fermentación anaerobia y no se inhibiera el proceso fermentativo, debido a que valores de $\mathrm{pH}$ por debajo de 5 y por encima de 8 se corre el riesgo de inhibir el proceso de fermentación o incluso detenerlo. El primer y segundo día de fermentación se efectuó una medición en el cual el pH fue de 4 , esto debido a que en el periodo de arranque se produce gran cantidad de ácido orgánico en los digestores por la actividad de las bacterias acidógenicas y por eso apareció ese valor bajo de $\mathrm{pH}$, pero mientras proseguía la digestión el $\mathrm{pH}$ se fue elevando lentamente hasta estabilizarse en el parámetro óptimo.

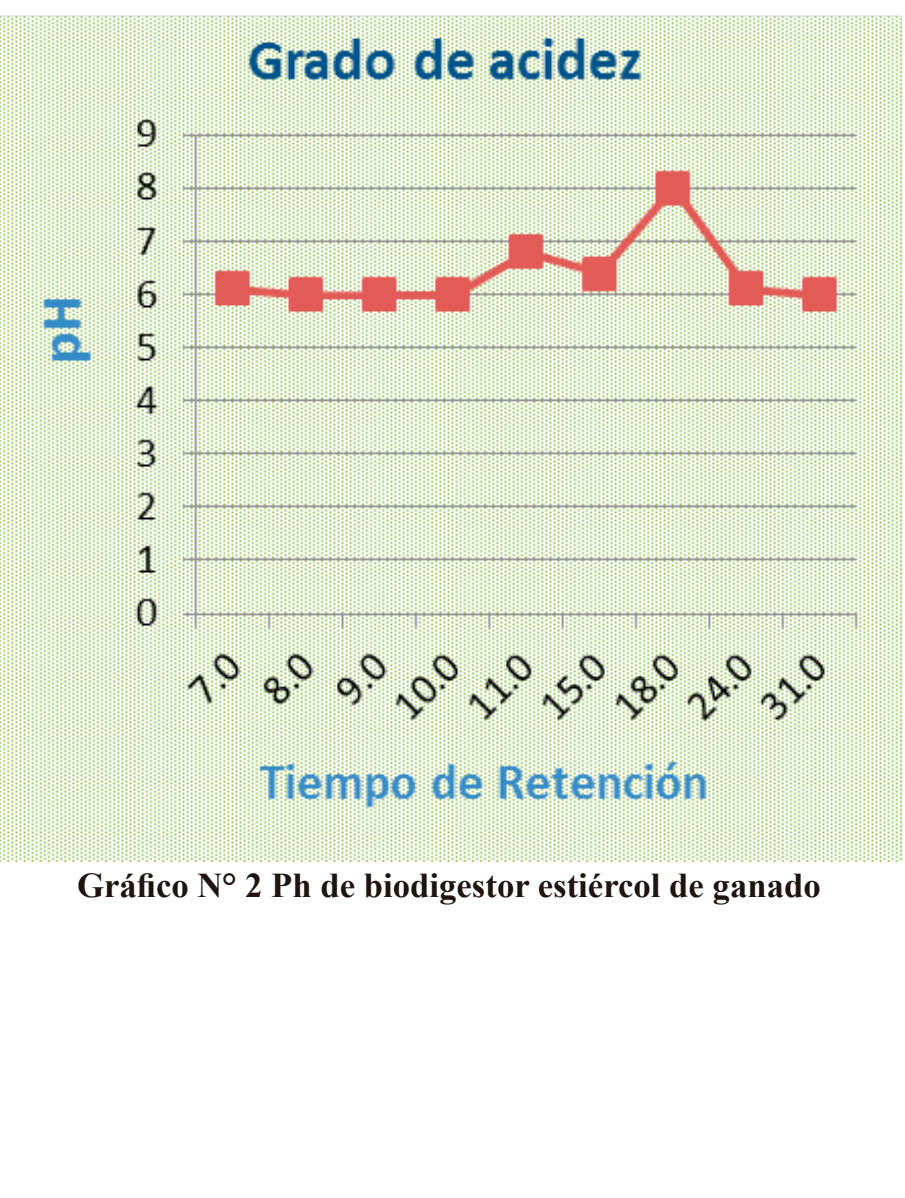




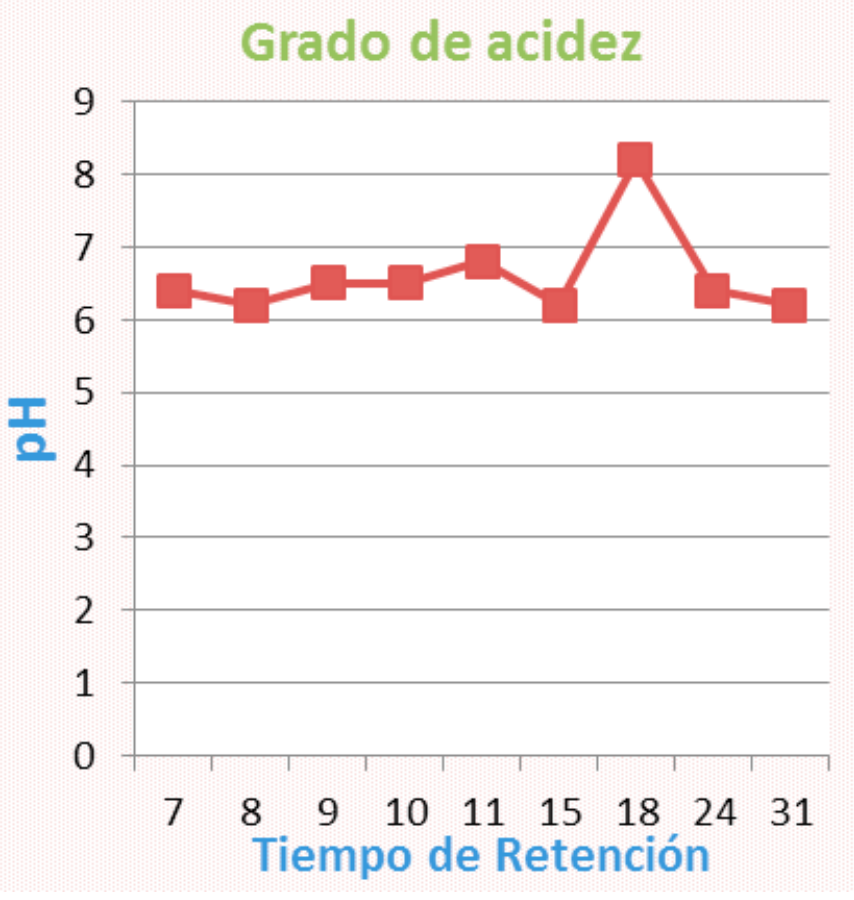

Gráfico $\mathrm{N}^{\circ} 3$ Ph de biodigestor biomasa 2:1

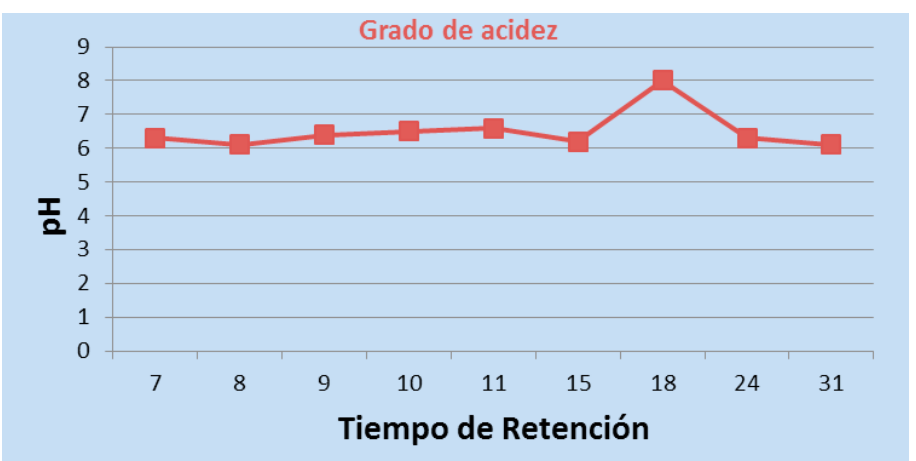

Gráfico $\mathrm{N}^{\circ} 4 \mathrm{Ph}$ de biodigestor biomasa 3:1

\section{Determinar la producción de biogás generada en el biodigestor}

La metodología utilizada para medir la cantidad de biogás producido se describe en el diseño metodológico. Los gráficos de la producción de biogás representa el volumen en ml obtenido durante la evaluación con un tiempo de retención de 7 días durante el cual se dio inicio la producción de biogás. (Ver anexo2)

Cabe señalar que según registro de la producción de biogás (gráficos 5,6 y 7), esta aumentaba los primeros días de la medición y luego va cayendo lo que representa una gráfica lineal todo relacionado con la temperatura y el $\mathrm{pH}$ los cuales se describieron en el resultado anterior, por lo que podemos decir que la producción de biogás depende directamente de la temperatura y la estabilización del pH.

La grafica 8 nos muestra el total producido a lo largo de la evaluación que se realizó hasta que se detuvo el proceso de fermentación, el reactor con biomasa y relación 2:1 fue del que se obtuvo el mayor rendimiento de biogás, aunque la diferencia no es tan significativa respecto al reactor con biomasa y relación 3:1, no obstante también se obtiene producción del reactor con estiércol de vaca el cual ya ha sido utilizado en biodigestores rurales y que ha dado muy buenos resultados, la diferencia radica en que el ganado se come la biomasa y le extrae la energía contenida en la misma y luego es depositada a los campos en excremento, mientras tanto el reactor de biomasa aprovecha esa energía contenida para la producción de biogás de ahí el argumento del por qué se obtuvieron mejores rendimientos en los reactores de biomasa.

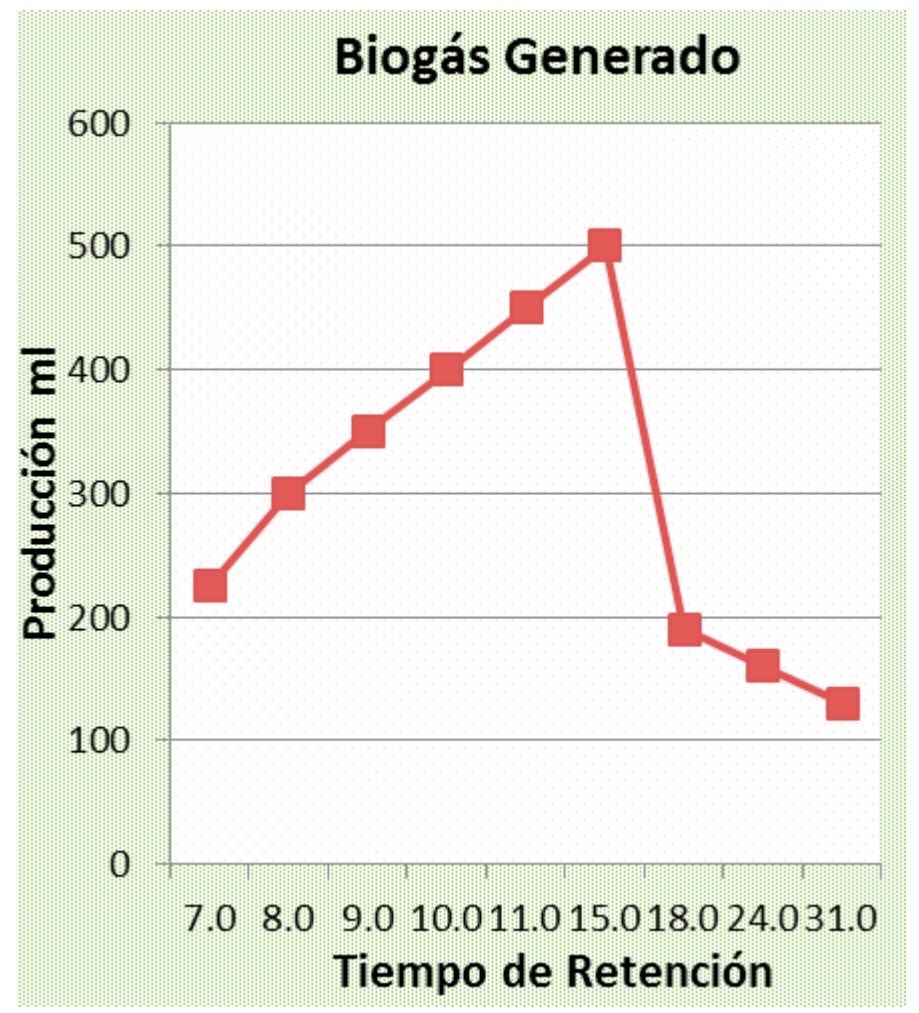

Gráfico N 5 Biogás estiércol de ganado 


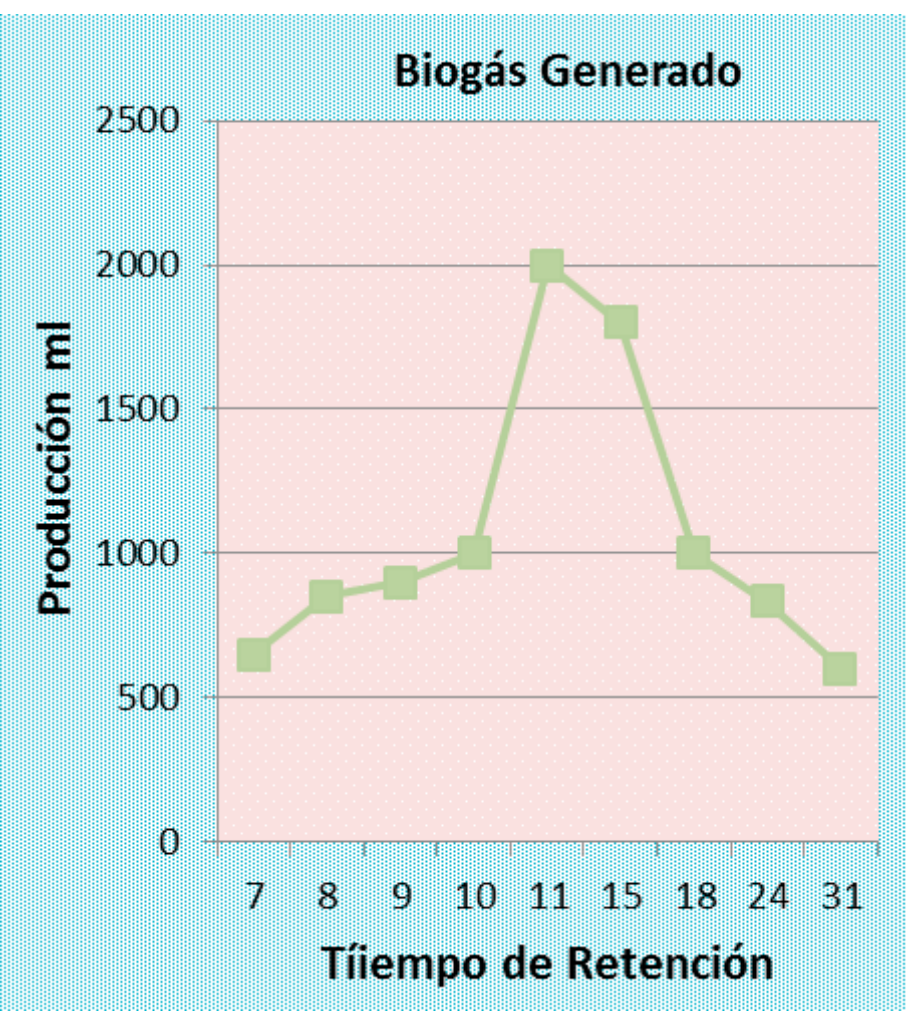

Gráfico $N^{\circ} 6$ Biogás biomasa 2:1

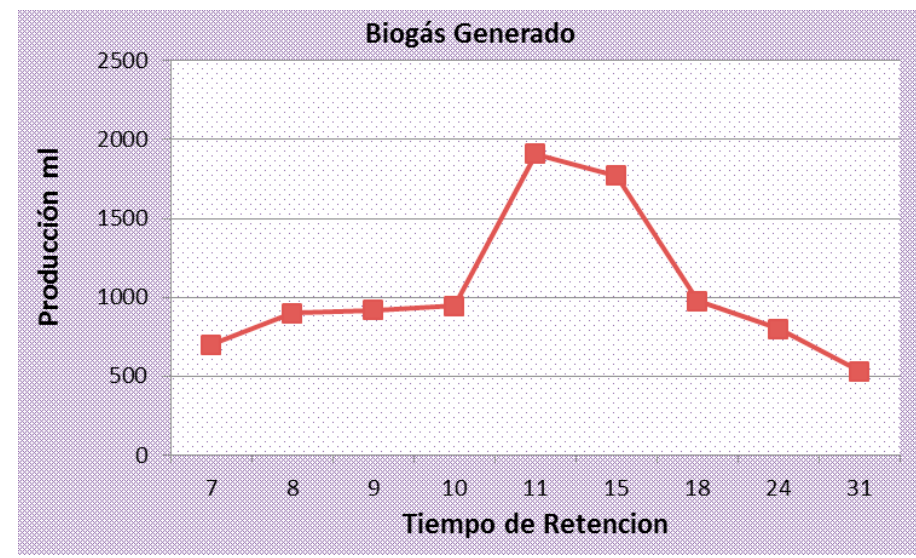

Gráfico Nº 7 Biogás biomasa 3:1

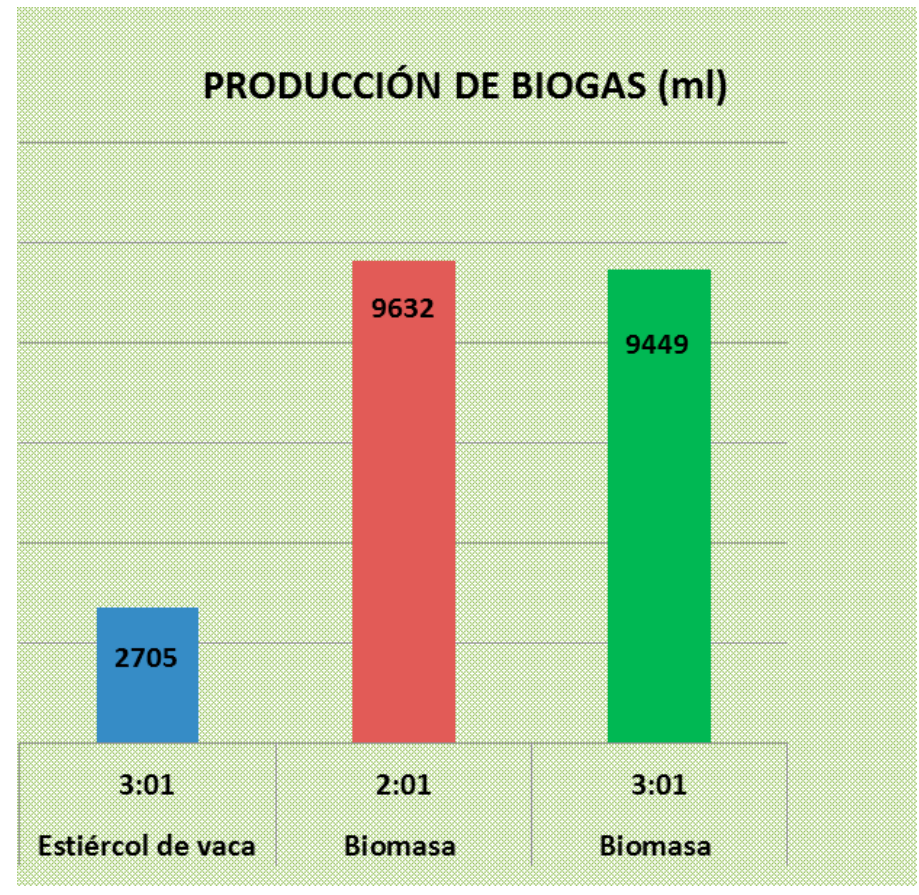

Gráfico $N^{\circ} 8$ Producción de biogás

\section{CONCLUSIONES}

En el país se cuenta con una gran cantidad de biomasa los cuales en el futuro los podemos aprovechar para la generación de energía eléctrica y cocción de alimentos a partir de la obtención de biogás, esto permite que se despale menos árboles en la zonas donde se tenga incidencia con proyectos de esta naturaleza lo que garantiza la sostenibilidad del medio ambiente, al reducirse la presión ejercida sobre los bosques, así como la emisión de nocivos gases de efecto invernadero, con ello, se demuestra la contribución del Proyecto al Objetivo de Desarrollo del Milenio $N^{0} 7$.

Esta investigación demuestra que la biomasa es un excelente sustrato para la producción de biogás siempre y cuando los parámetros que caracterizan la digestión anaerobia sean los adecuados para dicho proceso, el cual se logra construyendo un biodigestor con las características físicas y técnicas apropiadas.

Con la producción del biogás utilizando como materia prima el sustrato estudiado, se concluye que es urgente aprovechar estos materiales orgánicos, abundantes 
en las zonas rurales de nuestro país, para facilitar alternativas de energía a bajo costo al medio rural.

Los parámetros de funcionamiento evaluado dan la pauta de que se pueden mejorar las condiciones del proceso anaerobio utilizando biomasa por lo que es un tema que se puede seguir investigando e inclusive hacer proyectos piloto en zonas rurales.

Las condiciones climáticas tropicales, favorecen grandemente para la implementación de esta tecnología, debido a que a mayor temperatura, se produce una mayor degradación de la materia orgánica y disminuye el tamaño de las estructuras que requiere el sistema.

Se necesita establecer plantas pilotos de experimentación sobre la digestión anaeróbica, para poder generar conocimientos sobre la fermentación metanogénica ya que en la mayoría de nuestro país se conoce muy poco de los beneficios que tiene el tratar adecuadamente estos sustratos.

Se debe tener especial cuidado con aquellos sustratos con alto contenido de lignina no son directamente aprovechables y por lo tanto deben someterse a tratamientos previos (cortado, macerado, compostado) a fin de liberar las sustancias factibles de ser transformadas de las incrustaciones de lignina.

Es de suma importancia la difusión de la producción de biogás, para que sea conocida y comprendida por toda la población, especialmente la rural, para ello es necesario que tanto el Ministerio de Educación, Universidades y Organismos No gubernamentales, propicien a la educación secundaria y superior temas de investigación, referentes al tratamiento de desechos orgánicos para la producción de biogás y que además estos centros se conviertan en difusores y extensionistas de esta tecnología.

\section{AGRADECIMIENTOS}

Este estudio se llevó a cabo gracias al financiamiento del Programa de Naciones Unidas (PNUD)

\section{BIBLIOGRAFÍA DE REFRENCIA}

BUN-CA. (2002). Manuales sobre energía renovable: Biomasa. San Jose, Costa Rica: Bunca CA.

Contreras, L. (2006). Producción de biogás con fines energéticos. De lo histórico a lo estratégico.

Córdova, U., \& Castro, A. (2012). Genero y cocinas mejoradas. Lima.

Gengel, Y. A. (2005). Transferencia de calor. Monterrey,Mexico: Programas educativos S.A.

González Expósito, J. O. (2013). Estudio comparativo de cocinas mejoradas en Nicaragua. Valencia.

Guevara, V.A. (1996). Producción de gas y saneamiento de efluentes.

Hilbert., Jorge A. (2007). Manual para la producción de biogás. Mexico: Castelar 2007.

Holman, J. (1998). Transferencia de calor. . Madrid, España : McGraw - Hill .

Ing.Saballos Robles Alexander Roger - Ing. Tercero Martinez José Alexis. (2009). Estudio técnico y diseño de una planta de producción de biogás para generar eléctricidad para abastecer el consumo de energía eléctrica de una granja porcina del municipio de Estelí. Estelí.

Jarauta L. (2005). Digestión anaerobia para el tratamiento de residuos organicos. El caso de Perú. Escuela técnica de Ingeniería industrial. Barcelona ,España.

Korc, M., \& Quiñones, M. (2003). Diagnostico comparativo de la calidad del aire de los interiores de las viviendas de dos poblaciones indigenas del Peru. Lima.

Lugones lopez, B. (2001). Análisis de biodigestores; Especialista de Cuba energía. Miembro de Cubasolar. Cuba.

Martí rosas, R. G.-C. (2009). Máster en Energía para el desarrollo sostenible. Módulo 4 Energía Solar 
Térmica. Catalunya: Asthriesslav Rocuts.

Morales, I. M., Blanco Acevedo, V., \& García Nieto, A. (2010). Calidad del aire interior en edificios de uso público (primera ed.).

P. Sanchez García . (2006). La biomasa y la energía. Mexico.

Pilco Mamani, V. (2009). Proyecto de reglamento para la evaluación y certificacion de cocinas mejoradas. Lima.
Singh, R. B. (1974). The biogas plant. Generating methane from organic wastes. Ajitmal, India: U.P. Soriano, N. G. (2008). Biomasa. Barcelona.

Valdivia Tapia, R. V. (2000). Uso de Biogás para la generación de energía eléctrica mediante un motor gasolinero estacionario modificado.

Werner, E. (1983). Bioconversiòn: Producciòn de energìa utilizando desperdicios agricolas (Primera ed.). La Paz, Bolivia: FAO. 